\title{
$N$-Acylhomoserine lactones involved in quorum sensing control the type VI secretion system, biofilm formation, protease production, and in vivo virulence in a clinical isolate of Aeromonas hydrophila
}

Correspondence

Ashok K. Chopra

achopra@utmb.edu
Received 9 June 2009

Revised 31 August 2009

Accepted 2 September 2009
Bijay K. Khajanchi, ${ }^{1}$ Jian Sha, ${ }^{1}$ Elena V. Kozlova, ${ }^{1}$ Tatiana E. Erova, ${ }^{1}$ Giovanni Suarez, ${ }^{1}$ Johanna C. Sierra, ${ }^{1}$ Vsevolod L. Popov, ${ }^{2}$ Amy J. Horneman ${ }^{3}$ and Ashok K. Chopra ${ }^{1}$

\author{
${ }^{1}$ Department of Microbiology and Immunology, University of Texas Medical Branch, Galveston, TX \\ 77555-1070, USA \\ ${ }^{2}$ Department of Pathology, University of Texas Medical Branch, Galveston, TX 77555-1070, USA \\ ${ }^{3}$ Department of Medical and Research Technology, University of Maryland School of Medicine, \\ Baltimore, MD 21201, USA
}

\begin{abstract}
In this study, we delineated the role of $N$-acylhomoserine lactone(s) (AHLs)-mediated quorum sensing (QS) in the virulence of diarrhoeal isolate SSU of Aeromonas hydrophila by generating a double knockout $\Delta a h y R /$ mutant. Protease production was substantially reduced in the $\Delta a h y R I$ mutant when compared with that in the wild-type (WT) strain. Importantly, based on Western blot analysis, the $\Delta a h y R I$ mutant was unable to secrete type VI secretion system (T6SS)-associated effectors, namely haemolysin coregulated protein and the valine-glycine repeat family of proteins, while significant levels of these effectors were detected in the culture supernatant of the WT $A$. hydrophila. In contrast, the production and translocation of the type III secretion system (T3SS) effector AexU in human colonic epithelial cells were not affected when the ahyR/ genes were deleted. Solid surface-associated biofilm formation was significantly reduced in the $\Delta a h y R /$ mutant when compared with that in the WT strain, as determined by a crystal violet staining assay. Scanning electron microscopic observations revealed that the $\Delta a h y R I$ mutant was also defective in the formation of structured biofilm, as it was less filamentous and produced a distinct exopolysaccharide on its surface when compared with the structured biofilm produced by the WT strain. These effects of AhyRI could be complemented either by expressing the ahyRl genes in trans or by the exogeneous addition of AHLs to the $\Delta a h y R I / a h y R^{+}$complemented strain. In a mouse lethality experiment, $50 \%$ attenuation was observed when we deleted the ahyR/ genes from the parental strain of $A$. hydrophila. Together, our data suggest that AHL-mediated OS modulates the virulence of $A$. hydrophila SSU by regulating the T6SS, metalloprotease production and biofilm formation.
\end{abstract}

Abbreviations: AHL, N-acylhomoserine lactone; C4-HSL, N-3-butanoylDL-homoserine lactone; C6-HSL, N-3-hexanoyl-DL-homoserine lactone; $\mathrm{CV}$, crystal violet; $\mathrm{OS}$, quorum sensing; SEM, scanning electron microscopy; T2SS, type II secretion system; T3SS, type III secretion system; T6SS, type VI secretion system.

The GenBank/EMBL/DDBJ accession number for the ahyR/ sequence of $A$. hydrophila SSU is DQ398101.

Four supplementary figures, showing cross streaks of $A$. hydrophila strains against a Chromobacterium violaceum CV026 reporter strain, Western blot analysis showing production of Act in the supernatant from A. hydrophila strains, measurement of biofilm mass by crystal violet staining formed on polystyrene by strains of $A$. hydrophila, and Western blot analysis showing production of Hcp2, are available with the online version of this paper.

\section{INTRODUCTION}

Aeromonas hydrophila is a human pathogen that causes both intestinal and extraintestinal infections (Galindo et al., 2006; Vila et al., 2003). The organism is resistant to water chlorination and several antibiotics, specifically when it aggregates in a biofilm, posing a potential public health threat. Furthermore, A. hydrophila produces a wide battery of virulence factors, which function together to cause disease in the host (Chopra \& Houston, 1999; Krovacek et al., 1994; Sha et al., 2002). We characterized three different enterotoxins from a diarrhoeal isolate SSU of $A$. hydrophila (Sha et al., 2002). The most potent of these was 
the cytotoxic enterotoxin (Act) (Ferguson et al., 1997), which is secreted via the type II secretion system (T2SS) and functions as a haemolysin, a cytotoxin or an enterotoxin, depending upon the target cells (Chopra \& Houston, 1999).

Recently, we showed the contribution of two other secretion systems, namely the type III secretion system (T3SS) and the type VI secretion system (T6SS), in the virulence of $A$. hydrophila SSU (Sha et al., 2005, 2007; Sierra et al., 2007; Suarez et al., 2008), and reported the identification of a novel T3SS effector, AexU, which leads to the ADP-ribosylation of host cell proteins, resulting in their death via apoptosis (Sierra et al., 2007). AexU also inhibits bacterial phagocytosis by macrophages and induces mouse lethality (Sha et al., 2007). Likewise, the virulence-associated genes $v a s H$ and $v a s K$ are essential components of the T6SS, and our laboratory has provided evidence that isogenic mutants deleted for these genes are less virulent in a septicaemic mouse model of $A$. hydrophila SSU infection (Suarez et al., 2008). Recently, two T6SSassociated effectors, haemolysin co-regulated protein (Hcp) and the valine-glycine repeat $\mathrm{G}$ (VgrG) family of proteins, have been characterized, and their roles in the virulence of several pathogens established (Cascales, 2008; Mougous et al., 2006; Pukatzki et al., 2006, 2009).

We have demonstrated that deletion of the vasH gene prevents expression of the $h c p$ gene, which indicates to us that the former is a regulator of the T6SS in A. hydrophila SSU (Suarez et al., 2008). The genome of Vibrio cholerae contains three genes ( $\operatorname{vgrG1}, \operatorname{vgrG} 2$ and $\operatorname{vgrG3}$ ) that encode VgrG proteins, and mutations in the $h c p$ gene block secretion of all of these VgrG proteins (Pukatzki et al., 2006). Likewise, inactivation of the $\operatorname{vgrG}$ genes blocks secretion of Hcp (Pukatzki et al., 2006). This mutual dependence for secretion of Hcp and VgrGs has also been reported in other pathogens, such as Edwardsiella tarda and enteroaggregative Escherichia coli (EAEC) (Dudley et al., 2006; Pukatzki et al., 2007; Zheng \& Leung, 2007). It has been speculated that the VgrG proteins assemble into a trimeric complex that functions like a phage tail spike structure protein by forming a cell-puncturing device to deliver effector proteins into the host cells (Pukatzki et al., 2007).

A cell-to-cell signalling system, known as quorum sensing (QS), may be implicated in controlling many of these virulence factors, including T3SS and T6SS effectors, at appropriate times, depending on the physiological conditions in the environment as well as in the host. In Gramnegative bacteria at least, three QS systems have been identified and designated LuxRI (AI-1), LuxS/AI-2 and AI3 epinephrine/norepinephrine (Bassler \& Losick, 2006; Reading \& Sperandio, 2006; Waters \& Bassler, 2006). The $N$-acylhomoserine lactone (AHL) QS system has been identified in both human (Kirwan et al., 2006; Smith et al., 2002; Swift et al., 1999) and plant pathogens (Hussain et al., 2008; Liu et al., 2008). In different bacterial species, various types of AHLs have been detected that differ in the number of carbon atoms (C4-C18) and substitution at the C3 of the acyl side chain (Kumari et al., 2008).

An earlier study indicated that $A$. hydrophila produces two types of AHLs, namely N-3-butanoyl-DL-homoserine lactone (C4-HSL) and $\mathrm{N}$-3-hexanoyl-DL-homoserine lactone (C6-HSL), of which C4-HSL was the predominant type (Swift et al., 1997). Furthermore, AHLs that are synthesized by the LuxI protein family diffuse freely inside and outside of bacterial cells. At a certain critical threshold concentration, AHLs bind to their cognate receptors, in the LuxR protein family, and regulate the expression of the luxI gene for their synthesis, as well as control expression of many genes involved in biofilm formation, production of pigment and antibiotics, and virulence of the pathogen (de Kievit \& Iglewski, 2000; Greenberg, 1997). Importantly, AhyR functions as both a negative and a positive regulator of the ahyI gene in A. hydrophila (Kirke et al., 2004).

Microarray analyses have revealed the differential transcription of $26 \%$ of the genome in Pectobacterium atrosepticum (a plant pathogen) and $6 \%$ of the genome in Pseudomonas aeruginosa in EspI and LasI-RhlI mutants, respectively, compared with their corresponding parental strains. These data suggest that AHL-mediated QS is a master regulator for many genes in these pathogens (Liu et al., 2008; Schuster et al., 2003). In addition, the role of AHL-mediated QS control in the T3SS and T6SS of $P$. aeruginosa and other pathogens has been investigated and reported (Bleves et al., 2005; Gelhaus et al., 2009; Henke \& Bassler, 2004; Liu et al., 2008; Schuster et al., 2003). Although by microarray analysis it has been shown that the expression of the $h c p$ gene is reduced in the lasR-rhlR mutant, when compared with that in WT P. aeruginosa, it was not known at the time that Hcp was an effector of the T6SS (Schuster et al., 2003).

Specifically, we have shown that AHL production is significantly decreased when we delete two major virulence factor-encoding genes, such as act and an outer-membrane protein $(a \circ p B)$, an important component of the T3SS in A. hydrophila SSU (Sha et al., 2005). We also observed that lactone production is modulated by regulatory genes such as dam (DNA adenine methyltransferase) and gidA (glucose-inhibited division A) in A. hydrophila SSU (Erova et al., 2006a). These data prompted us to further investigate the regulatory role of AHL-mediated QS in the virulence of $A$. hydrophila SSU.

Our studies have been substantiated by previous reports showing that AHL-mediated QS regulates exoprotease production (Swift et al., 1999) and biofilm formation (Lynch et al., 2002) in A. hydrophila. In addition, the $a h y R$ mutant of $A$. hydrophila $\mathrm{J}-1$ is significantly attenuated in a fish infection model (Bi et al., 2007). However, the role of AHL-mediated QS in clinical isolates of A. hydrophila has never been tested in a mouse model of infection, and the role of QS in modulating the T3SS and T6SS is largely unknown in this pathogen. 
Consequently, in this study, we identified AhyRI (LuxRI homologue) in a clinical isolate SSU of A. hydrophila as a result of our annotation of the genome sequence of an environmental isolate ATCC 7966 of A. hydrophila (Seshadri et al., 2006). We showed that disruption of the ahyRI genes in A. hydrophila SSU influenced metalloprotease production, secretion of the T6SS effectors (Hcp and VgrGs), biofilm formation, and mortality in a mouse model of infection. Our study is the first, to our knowledge, to document that AHL mediates the QSregulated secretion of the newly discovered T6SS effectors in A. hydrophila SSU and, based on zymography, that the production of a metalloprotease is specifically reduced in the $\triangle a h y R I$ mutant.

\section{METHODS}

Bacterial strains, plasmids, and chemicals. The bacterial strains and plasmids used in this study are listed in Table 1. Chemically synthesized C4-HSL and C6-HSL were obtained from Fluka. Stock solutions $(50 \mathrm{mM})$ of AHLs were prepared by dissolving them in acetonitrile (far-UV grade), and stocks were stored at $-20{ }^{\circ} \mathrm{C}$.

Generation and characterization of the $\Delta a h y R I$ mutant of $\boldsymbol{A}$. hydrophila SSU. Based on DNA sequences of the ahyI/ahyR genes (homologues of the luxI/luxR genes) in the A. hydrophila ATCC 7966 strain, two primers (ahyR, 5' -TTATTGCATCAGCTTGGGGAAG-3', and ahyI, 5'-TTATTCGGTGACCAGTTCGCG-3') were synthesized. By using these primers, a $1.5 \mathrm{~kb}$ DNA fragment was PCR-amplified from the genome of A. hydrophila SSU and subsequently cloned in the TA cloning vector pCR2.1 (Invitrogen). DNA sequence analysis revealed that this fragment was 1469 bp long and contained the entire $a h y R I$ operon. By using restriction enzyme StuI (generating blunt ends), we removed a $443 \mathrm{bp}$ DNA fragment from within the ahyRI operon harboured in the TA cloning vector, and replaced it with the blunt-ended $2.0 \mathrm{~kb} \mathrm{Sm}{ }^{\mathrm{R}} / \mathrm{Sp}^{\mathrm{R}}$ gene cassette from plasmid $\mathrm{pHP} 45 \Omega$ (Prentki \& Krisch, 1984), which was obtained by SmaI restriction enzyme digestion. This strategy resulted in a 185 and a $196 \mathrm{bp}$ deletion from the start codons of the ahyI and ahyR genes, respectively. The $\mathrm{Sm}^{\mathrm{R}} / \mathrm{Sp}^{\mathrm{R}}$-truncated ahyRI genes were removed from the pCR2.1 vector by $K p n I / X b a I$ digestion and ligated to the pDMS197 suicide vector at compatible restriction enzyme sites. The resulting plasmid (pDMS197ahyRISm/Sp) was transformed into $E$. coli SM10, which contained $\lambda$ pir (Edwards et al., 1998). The recombinant E. coli (pDMS197ahyRI-Sm/Sp) cells were then conjugated with WT A. hydrophila SSU-R (Sha et al., 2002). The transconjugants were selected based on resistance to appropriate antibiotics and sucrose and their genomic DNA (gDNA) subjected to Southern blot analysis for their correct identification, as described previously (Sha et al., 2002).

Complementation of the A. hydrophila SSU $\triangle$ ahyRI mutant. The ahyRI genes were PCR-amplified by using gDNA of $A$. hydrophila as a template and two primers (ahyRI-N/SalI, 5'-GGGGTCGACAGCAGCTTGTAATCCAACGC-3', and ahyRI-C/EcoRI, 5'-GGGGAATTCATGAACCGTCCAGCAGAGTGA-3'; restriction endonuclease $\overline{\text { sites }}$ underlined). We included $293 \mathrm{bp}$ of the upstream and $210 \mathrm{bp}$ of the downstream DNA flanking sequences containing potential promoter regions of divergent ahyRI genes for complementation studies. This DNA fragment (1972 bp) was cloned in the pBR322 vector $\left(\mathrm{Tc}^{\mathrm{r}} \mathrm{Ap}^{\mathrm{r}}\right)$ at SalI-EcoRI sites and transformed into the E. coli $\mathrm{DH} 5 \alpha$ strain. The $\mathrm{pBR} 322 /$ ahyRI $\left(\mathrm{Tc}^{\mathrm{s}} \mathrm{Ap}^{\mathrm{r}}\right)$ recombinant plasmid was isolated from the E. coli strain and electroporated into an $A$. hydrophila $\triangle a h y R I$ mutant.

Complementation of the ahyR gene in the A. hydrophila SSU $\Delta$ ahyRI mutant. To complement the ahyR gene in the double mutant $\triangle a h y R I$ of $A$. hydrophila, the ahyR gene was amplified with the following primers: ahyR-N/ScaI, 5'-GGGAGTACTATGAAACAAGACCAACTGCTT-3', and ahyR-C/PstI, 5' -GGGCTGCAGTTATTGCATCAGCTTGGGGA-3'. The DNA fragment (783 bp) was cloned in

Table 1. Strains and plasmids used in this study

\begin{tabular}{|c|c|c|}
\hline Strain or plasmid & Relevant characteristic(s) & Source or reference \\
\hline A. hydrophila SSU strains & & CDC, Atlanta, GA, USA \\
\hline SSU-R & Rifampin-resistant $\left(\mathrm{Rif}^{\mathrm{R}}\right)$ strain of $A$. hydrophila SSU & Laboratory stock \\
\hline$\Delta a h y R I$ & ahyRI gene deletion mutant of $A$. hydrophila SSU-R strain, $\operatorname{Rif}^{\mathrm{R}} \mathrm{Sm}^{\mathrm{R}} \mathrm{Sp}^{\mathrm{R}}$ & This study \\
\hline$\Delta a h y R I / p B R 322-a h y R I$ & ahyRI mutant complemented with ahyRI genes via pBR322, $\operatorname{Rif}^{\mathrm{R}} \mathrm{Sm}^{\mathrm{R}} \mathrm{Sp}^{\mathrm{R}} \mathrm{Ap}^{\mathrm{R}}$ & This study \\
\hline$\Delta a h y R I / p B R 322-a h y R$ & ahyRI mutant complemented with ahyR gene via $\mathrm{pBR} 322, \mathrm{Rif}^{\mathrm{R}} \mathrm{Sm}^{\mathrm{R}} \mathrm{Sp}^{\mathrm{R}} \mathrm{Tc}^{\mathrm{R}}$ & This study \\
\hline \multicolumn{3}{|l|}{ E. coli strains } \\
\hline $\mathrm{DH} 5 \alpha$ & Production of recombinant plasmids, $r e c A, g y r A$ & Life Technologies \\
\hline SM10 & $\mathrm{Km}^{\mathrm{R}}, \lambda$ pir & Edwards et al. (1998) \\
\hline \multicolumn{3}{|l|}{ C. violaceum strain } \\
\hline CV026 & ATCC 31532 derivative, cviI: : Tn $5 x y l E ; \mathrm{Km}^{\mathrm{R}} \mathrm{Sm}^{\mathrm{R}}$ & McClean et al. (1997) \\
\hline \multicolumn{3}{|l|}{ Plasmids } \\
\hline pCR2.1 & TA cloning vector, $\mathrm{Ap}^{\mathrm{R}} \mathrm{Km}^{\mathrm{R}}$ & Invitrogen \\
\hline pCR2.1/ahyRI & TA cloning vector carrying ahyRI gene, $\mathrm{Ap}^{\mathrm{R}} \mathrm{Km}^{\mathrm{R}}$ & This study \\
\hline $\mathrm{pHP} 45 \Omega$ & pHP45 plasmid containing a $2 \mathrm{~kb} \mathrm{Sm}^{\mathrm{R}} / \mathrm{Sp}^{\mathrm{R}}$ gene cassette ( $\Omega$ element $)$ & Prentki \& Krisch (1984) \\
\hline $\mathrm{pCR} 2.1 /$ ahyRI-Sm/Sp & TA cloning vector harbouring ahyRI gene disrupted by $\Omega$ element, $\mathrm{Ap}^{\mathrm{R}} \mathrm{Sm}^{\mathrm{R}} \mathrm{Sp}^{\mathrm{R}}$ & This study \\
\hline pDMS197 & Suicide vector, R6K ori, $s a c B, \mathrm{Tc}^{\mathrm{R}}$ & Edwards et al. (1998) \\
\hline $\mathrm{pDMS197/ahyRI-Sm/Sp}$ & Suicide vector containing ahyRI gene with $\Omega$ element, $\mathrm{Tc}^{\mathrm{R}} \mathrm{Sm}^{\mathrm{R}} \mathrm{Sp}^{\mathrm{R}}$ & This study \\
\hline pBR322 & $\mathrm{Ap}^{\mathrm{R}} \mathrm{Tc}^{\mathrm{R}}$ & Amersham \\
\hline pBR322/ahyRI & Contains ahyRI gene, Ap ${ }^{\mathrm{R}}$ & This study \\
\hline pBR322/ahyR & Contains ahyR gene, $\mathrm{Tc}^{\mathrm{R}}$ & This study \\
\hline
\end{tabular}


the pBR322 vector $\left(\mathrm{Tc}^{\mathrm{R}} \mathrm{Ap}^{\mathrm{R}}\right)$ at ScaI/PstI sites and transformed into E. coli strain $\mathrm{DH} 5 \alpha$. The pBR322/ahyR $\left(\mathrm{Tc}^{\mathrm{R}} \mathrm{Ap}^{\mathrm{S}}\right)$ recombinant plasmid was isolated from the E. coli strain and electroporated into the A. hydrophila $\triangle a h y R I$ mutant.

Lactone production. AHL production was detected by crossstreaking of the WT, $\triangle a h y R I$ mutant and complemented strains of A. hydrophila SSU on LB agar medium against the biosensor strain Chromobacterium violaceum CV026, as described elsewhere (McClean et al., 1997).

Measurement of protease activity. Protease activity was measured in culture filtrates of overnight-grown cultures of WT A. hydrophila, $\triangle a h y R I$ mutant and the complemented strains $\left(\Delta a h y R I / a h y R^{+} a h y I^{+}\right.$ and $\Delta a h y R I / a h y R^{+}$) as described previously (Erova et al., 2006b). The protease activity was calculated per millilitre of culture filtrate per $10^{8}$ c.f.u. To determine the nature of proteases, we used metallo and serine protease inhibitors EDTA and PMSF at final concentrations of 100 and $10 \mathrm{mM}$, respectively. The proteases were inactivated with their corresponding inhibitors for $2 \mathrm{~h}$ at $37{ }^{\circ} \mathrm{C}$ before measuring the activity. To characterize the nature of protease(s) and to delineate which specific protease(s) was affected in the $\Delta a h y R I$ mutant, we performed casein zymography using established procedures (Nicodème et al., 2005; Swift et al., 1999).

Measurement of haemolytic activity. The haemolytic activity associated with Act of WT A. hydrophila SSU and its $\Delta a h y R I$ mutant strain was measured as previously described (Sha et al., 2002). For the neutralization assay, culture filtrates of WT and $\Delta a h y R I$ mutant strains were mixed with either pre-immune (control) or hyperimmune rabbit sera (laboratory stock, 1:10 dilution) containing antibodies to Act (Erova et al., 2007).

Measurement of cytotoxic activity. RAW 264.7 murine macrophages were infected at an m.o.i. of 5 with the WT A. hydrophila SSU and its $\triangle a h y R I$ mutant strain. During infection, cell morphology was monitored, and at various time points after infection, host cell cytotoxicity associated with Act or T3SS and T6SS effectors was measured in the tissue culture supernatant by the release of lactate dehydrogenase (LDH) enzyme using a CytoTox 96 kit (Promega) (Sha et al., 2005).

Swimming and swarming motility assay. LB medium with $0.3 \%$ Difco Bacto-agar (Difco Laboratories) was used to characterize the swimming motility (Kozlova et al., 2008), while Difco nutrient broth with $0.5 \%$ Eiken agar (Eiken Chemical) was employed for measuring swarming motility (Kirov et al., 2002) of WT A. hydrophila SSU and its $\Delta a h y R I$ mutant strain. The A. hydrophila ATCC 7966 strain (Seshadri et al., 2006), which does not possess genes encoding the lateral flagellum, was used as a negative control in the swarming motility assay.

Crystal violet (CV) biofilm assay. As a modification of the biofilm ring assay (O'Toole \& Kolter, 1998), the WT, $\Delta a h y R I$ mutant and $\Delta a h y R I / a h y R^{+} a h y I^{+}$and $\Delta a h y R I / a h y R^{+}$complemented strains of $A$. hydrophila were grown directly from the $-80{ }^{\circ} \mathrm{C}$ stock in $3 \mathrm{ml} \mathrm{LB}$ medium contained in polystyrene tubes at $37{ }^{\circ} \mathrm{C}$ for $24 \mathrm{~h}$ with shaking. The $\Delta a h y R I / a h y R^{+}$complemented strain was grown in the presence of $20 \mu \mathrm{M}$ C4-HSL. Biofilm formation was quantified according to the procedure described elsewhere (Morohoshi et al., 2007). Finally, the biofilm formation results were normalized to $1 \times 10^{9}$ c.f.u. to account for any differences in the growth rates of various bacterial strains used. The experiment was repeated independently three times.

Scanning electron microscopy (SEM) biofilm experiments. SEM on biofilm formation was performed using $13 \mathrm{~mm}$ diameter
Thermanox plastic coverslips. After $48 \mathrm{~h}$ incubation, unattached cells were removed, the coverslips were fixed and stained with ruthenium red, and samples were examined in a Hitachi S4700 field emission scanning electron microscope (Hitachi High Technologies America) according to the procedure described in our previous study (Kozlova et al., 2008).

Western blot analysis. Overnight cultures of the WT, $\Delta a h y R I$ mutant and complemented strains were diluted $1: 20$ in fresh LB medium and grown for $2 \mathrm{~h}\left(\mathrm{OD}_{600} \sim 0.8\right)$ and $4 \mathrm{~h}\left(\mathrm{OD}_{600} \sim 1.4\right)$ at $37{ }^{\circ} \mathrm{C}$ with shaking at 180 r.p.m. The $\Delta a h y R I / a h y R^{+}$complemented strain was grown in the presence of $20 \mu \mathrm{M}$ C4-HSL. To measure protein levels in the cells, $2 \mathrm{ml}$ culture was pelleted $(10000 \mathrm{~g}$ for $10 \mathrm{~min}$ at $4{ }^{\circ} \mathrm{C}$ ) and dissolved in $200 \mu \mathrm{l} 2 \times$ sample buffer. To measure secretion of the proteins in the LB medium, $2 \mathrm{ml}$ supernatants were separated from the pellet and filtered through a $0.22 \mu \mathrm{m}$ pore-size membrane filter. Proteins present in the supernatant fraction were precipitated with TCA (10\% final concentration) and pelleted by high-speed centrifugation at $14000 \mathrm{~g}$ for $15 \mathrm{~min}$ at $4{ }^{\circ} \mathrm{C}$. The pellet was resuspended in $50 \mu \mathrm{l} 2 \times$ sample buffer.

Equal amounts of samples were subjected to SDS-PAGE, and Western blot analysis was performed using polyclonal antisera against Hcp2 and VgrG2 [1:1000 dilution in Tris-buffered saline (TBS)/0.5\% skimmed milk], as described previously (Suarez et al., 2008). We used antibodies to bacterial DnaK (bacterial cytosolic protein) as a control in Western blot analysis to demonstrate that the T6SS effectors in the culture supernatant were not released as a result of bacterial lysis (Sha et al., 2007).

We used recombinant VgrG2 for antibody production, and the immune sera obtained did not differentiate between VgrG2 and VgrG3 proteins of $A$. hydrophila SSU due to the high homology $(\sim 90 \%)$ between them and their similar sizes on Western blots.

To measure the expression and translocation of AexU, a T3SS effector, in HT-29 human colonic epithelial cells, we followed the methodology that we described previously (Sha et al., 2007).

Animal experiments. Groups of 10 Swiss Webster mice (Taconic Farms) were infected by the intraperitoneal (i.p.) route with $3 \times 10^{7}$ c.f.u. (WT or its $\Delta a h y R I$ mutant) in accordance with the approved animal care protocol. One group of mice was inoculated with Dulbecco's phosphate buffered saline (DPBS) $(n=10)$ and served as a control. Deaths were recorded for 16 days post-infection. This bacterial dose used represented approximately $2 \times \mathrm{LD}_{50}$ of WT $A$. hydrophila (Xu et al., 1998).

Statistics. Wherever applicable, at least three independent experiments were performed, and the data analysed by using Student's $t$ test, with $P$ values of $\leqslant 0.05$ considered significant. The animal data were analysed by using Fisher's exact test.

\section{RESULTS}

\section{Characterization of the AhyRI QS regulon in A. hydrophila SSU}

In an earlier study (Swift et al., 1997), a LuxRI homologue was identified in A. hydrophila A1 strain and designated AhyRI (GenBank accession no. X89469). By our sequence annotation of A. hydrophila ATCC 7966 (Seshadri et al., 2006), we identified $a h y R$ and $a h y I$ genes in a clinical isolate, A. hydrophila SSU, which had a 97 and $94 \%$ sequence homology with the corresponding genes of the $A$. 
hydrophila A1 strain, respectively. The ahyR and ahyI genes in A. hydrophila SSU were oppositely oriented with a $59 \mathrm{bp}$ intergenic region. Furthermore, a Pfam protein sequence search (http://pfam.sanger.ac.uk/) revealed that AhyR had two domains, one for autoinducer binding and the other a regulatory domain (Lux family).

To characterize the role of AHL-mediated QS in the regulation of virulence in A. hydrophila SSU, we deleted both the ahyR and ahyI genes by double crossover homologous recombination and subsequently generated a complemented strain with both of the ahyRI genes ( $\Delta a h y R I /$ $\left.a h y R^{+} a h y I^{+}\right)$. For further confirmation of interaction between AhyR and signalling molecules (AHLs) in modulating virulence factors, we also complemented the ahyR gene in the $\Delta a h y R I$ mutant strain $\left(\Delta a h y R I / a h y R^{+}\right)$and examined the restoration of phenotypic changes by the exogenous addition of AHLs. As expected, the $\Delta a h y R I$ mutant was unable to produce AHLs, which was examined by using $C$. violaceum CV026 as a biosensor strain (Supplementary Fig. S1a). Lactone production was restored in the $\Delta a h y R I$ complemented strain (Supplementary Fig. S1b).

\section{The $\Delta a h y R I$ mutant produced a reduced level of protease}

Earlier studies had indicated that the pathogenic and virulence characteristics of $A$. hydrophila are associated with the production of exoenzymes (e.g. proteases and lipases) (Chopra \& Houston, 1999; Janda \& Abbott, 1998). Consequently, we measured protease production, and the $\Delta a h y R I$ mutant strain produced a significantly reduced level of protease compared with that of the WT $A$. hydrophila strain (Table 2). Furthermore, the protease production was restored to the WT level in the $\Delta a h y R I$ complemented strain $\left(\Delta a h y R I / a h y R^{+} a h y I^{+}\right)$(Table 2). For further confirmation of complementation, protease production was also measured in the $\Delta a h y R I / a h y R^{+}$complemented strains when they were simultaneously supplied with two different exogenous AHLs (C4-HSL and C6HSL). We observed that addition of both of the exogenous lactones restored protease production (Table 2), which suggested to us that AHL molecules interacted with AhyR to control protease production in A. hydrophila SSU.

Based on casein zymography, we identified three protein bands with protease activity (with sizes of 61,52 and $19 \mathrm{kDa}$ ) in the culture filtrates of WT A. hydrophila SSU and its $\Delta a h y R I$ complemented strain $\left(\Delta a h y R I / a h y R^{+} a h y I^{+}\right)$. Importantly, $61 \mathrm{kDa}$ and $52 \mathrm{kDa}$ protease-associated protein bands were missing in the $\Delta a h y R I$ mutant (Fig. 1). Furthermore, we noted that the $61 \mathrm{kDa}$ band represented a metalloprotease, as treatment of the culture supernatants from WT A. hydrophila and its $\Delta a h y R I$ complemented strain with EDTA resulted in complete disappearance of this band (Fig. 1). The nature of the proteases associated with the 52 and $19 \mathrm{kDa}$ bands is unknown. Based on our enzyme assay, EDTA resulted in $81 \%$ loss of the total protease activity, while PMSF had minimal effect on the protease activity.
Table 2. Measurement of protease activity in culture supernatants and biofilm mass on polystyrene plastic of $A$. hydrophila SSU, the $\Delta a h y R I$ mutant and complemented strains

ND, Not determined.

\begin{tabular}{|c|c|c|}
\hline Strain & $\begin{array}{l}\text { Protease activity } \\
\left(\mathrm{OD}_{595} \mathrm{ml}^{-1} \text { per } 10^{8}\right. \\
\text { c.f.u. })(\text { mean } \pm \mathrm{SD})\end{array}$ & $\begin{array}{c}\text { Biofilm } \\
\text { formation }\left(A_{570}\right) \\
(\text { mean } \pm \text { SD })\end{array}$ \\
\hline A. hydrophila SSU & $1.20 \pm 0.23$ & $3.70 \pm 0.28$ \\
\hline$\Delta a h y R I$ & $0.11 \pm 0.04^{* \pm}$ & $0.55 \pm 0.07^{\star} \#$ \\
\hline$\Delta a h y R I / a h y R^{+} a h y I^{+}$ & $1.98 \pm 0.40^{* \S}$ & $2.50 \pm 0.28^{\star \dagger \dagger}$ \\
\hline $\begin{array}{l}\Delta a h y R I / a h y R^{+}+ \\
\text {C4-HSL }\end{array}$ & $1.41 \pm 0.18^{\star 11}$ & $3.90 \pm 0.14^{\star * \neq}$ \\
\hline $\begin{array}{l}\Delta a h y R I / a h y R^{+}+ \\
\text {C6-HSL }\end{array}$ & $0.56 \pm 0.03^{*}$ & $\mathrm{ND}$ \\
\hline
\end{tabular}

Protease activity: ${ }^{*}$ statistically significant differences between the $\triangle a h y R I$ mutant and the WT bacteria by Student's $t$ test $(P=0.001)$; ${ }^{*}$ between the $\triangle a h y R I$ mutant and $\Delta a h y R I / a h y R^{+}$ahyI $I^{+}$complemented strain $(P=0.001) ;{ }^{*}$, gbetween the $\Delta a h y R I$ mutant and $\Delta a h y R I /$ $a h y R^{+}$complemented strain with exogenous supply of C4-HSL or C6-HSL $(P<0.001)$.

Biofilm formation: ${ }^{*}$ \#statistically significant differences between the $\triangle a h y R I$ mutant and the WT bacteria $(P=0.004)$; ${ }^{* \dagger}$ between the $\triangle a h y R I$ mutant and $\triangle a h y R I / a h y R^{+} a h y I^{+}$complemented strain $(P=0.01)$; * between the $\Delta a h y R I$ mutant and $\Delta a h y R I / a h y R^{+}$ complemented strain with exogenous supply of C4-HSL $(P=0.001)$.

\section{Haemolytic and cytotoxic activities associated with Act were unaltered in the $\Delta a h y R I$ mutant}

The level of haemoglobin release from rabbit erythrocytes was identical in both the WT and the $\Delta a h y R I$ mutant strain of A. hydrophila SSU. To demonstrate that the lack of detection in reduction of Act-associated haemolytic activity was not due to the upregulation of other genes encoding haemolysin, we performed a haemolytic activity assay after neutralization of Act in the culture supernatant using specific antibodies. We noted that the level of residual haemolytic activity in the WT versus $\Delta a h y R I$ mutant strains remained unchanged, indicating that the expression of other haemolysin genes, in general, was not altered by deletion of the ahyRI genes. In addition, based on Western blot analysis, similar levels of Act were noted in the WT and the $\triangle a h y R I$ mutant strain of A. hydrophila SSU (Supplementary Fig. S2). Likewise, the $\Delta a h y R I$ mutant produced cytotoxic activity at a level similar to that of the WT bacteria (data not shown). These data suggested to us that the AhyRI QS regulon had no effect on Act-mediated biological activities in A. hydrophila SSU.

\section{Swimming and swarming motility of the $\Delta a h y R I$ mutant was unaffected}

A. hydrophila SSU WT strain had both swimming and swarming motility; however, the $\Delta a h y R I$ mutant migrated in a manner similar to that of the parental strain on the 


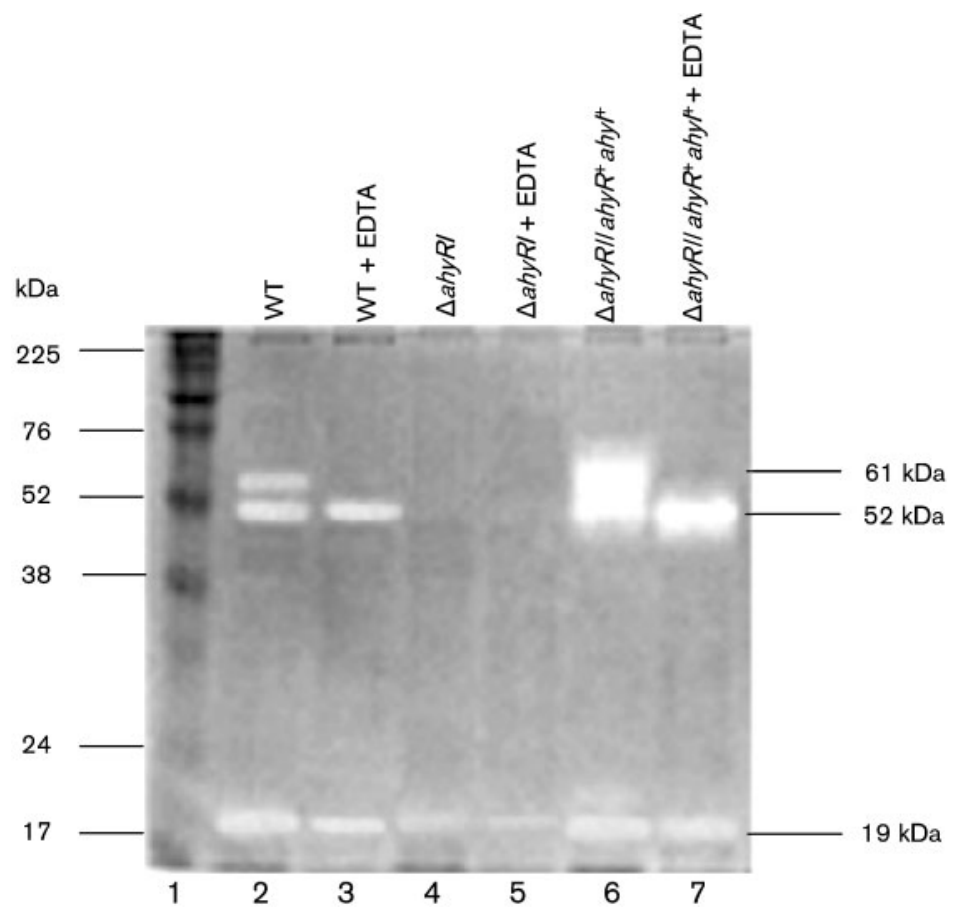

Fig. 1. Casein zymogram of supernatant proteins of WT $A$. hydrophila SSU, the $\triangle a h y R I$ mutant and its complemented strain. After incubation of the SDS-polyacrylamide gel $(12 \%)$ in $2 \%$ casein solution, Coomassie blue staining showed activity associated with proteases, which appeared as clear bands due to hydrolysis of casein on a blue background. Lanes: 1, molecular mass standard; 2, supernatant from WT $A$. hydrophila SSU; 3, supernatant from WT $A$. hydrophila SSU treated with EDTA; 4, supernatant from the $\triangle a h y R I$ mutant; 5, supernatant from the $\triangle a h y R /$ mutant treated with EDTA; 6, supernatant from the complemented strain ( $\Delta$ ahyRI/ ahy $R^{+}$ahyl $\left.{ }^{+}\right) ; \quad 7, \quad$ supernatant from the complemented strain $\left(\Delta a h y R / / a h y R^{+}\right.$ahyl $\left.{ }^{+}\right)$ treated with EDTA.

swimming and swarming agar plates (data not shown), which indicated that the swimming and swarming motility was not regulated by the AHL-mediated QS in $A$. hydrophila SSU.

\section{CV staining biofilm assay demonstrated attachment deficiency in the $\Delta a h y R I$ mutant}

To measure the solid surface-associated biofilm formation, we performed a CV staining assay after $24 \mathrm{~h}$ growth of the WT, $\Delta a h y R I$ mutant, and $\Delta a h y R I / a h y R^{+} a h y I^{+}$and $\Delta a h y R I / a h y R^{+}$(with exogenous AHLs) complemented strains in LB medium (Table 2). The $\Delta a h y R I$ mutant formed a significantly decreased solid surface-associated biofilm in polystyrene tubes (Table 2), with an $86 \%$ reduction in the $\mathrm{CV}$ staining when compared with that of the WT A. hydrophila SSU strain (Supplementary Fig. S3). The $\Delta a h y R I / a h y R^{+} a h y I^{+}$complemented strain adhered to the polystyrene tube in a manner similar to that of the WT bacteria (Supplementary Fig. S3). Addition of exogenous C4-HSL $(20 \mu \mathrm{M})$ also restored biofilm formation in the $\Delta a h y R I / a h y R^{+}$complemented strain (Table 2). These data suggested to us that AHL QS had a positive regulatory role on the biofilm formation in A. hydrophila SSU.

\section{A distinct architecture of biofilm was observed in the $\triangle a h y R I$ mutant when examined by SEM}

Exopolysaccharide (EPS), which consists of polysaccharides, DNA and proteins, plays an important role in determining biofilm architecture (de Kievit, 2009). To investigate the surface architecture of bacterial cells aggregated in biofilm formed by the WT and $\Delta a h y R I$ mutant, we performed SEM. Ruthenium red staining is an excellent method for visualization of surface properties of bacteria (Fassel \& Edmiston, 1999), and hence we stained bacterial aggregates with ruthenium red. As expected, SEM results revealed that WT bacteria formed a structured biofilm in which cells were well connected by filaments (Fig. $2 \mathrm{a}, \mathrm{c}$ and e). In contrast, the $\Delta a h y R I$ mutant was less filamentous, and it was not properly aggregated as was the parental strain (Fig. 2b, d and f). In addition, EPS produced by WT bacteria (indicated by arrow in Fig. 2e) was thick and tightly attached to the surface of the bacteria. On the other hand, EPS produced by the $\Delta a h y R I$ mutant (indicated by arrow in Fig. 2f) was loosely bound to bacterial cells. The $\Delta a h y R I$ complemented strains produced biofilms similar to that of the WT bacteria (data not shown). Overall, SEM images indicated that the $\Delta a h y R I$ mutant was defective in the production of mature biofilm compared with the parental strain, which suggested to us that AHL-mediated QS has a regulatory role in biofilm development of $A$. hydrophila SSU.

\section{AHL mediated the QS-controlled secretion of Hcp, a T6SS effector}

The T6SS is a novel secretion mechanism, and very little is known as to how effector proteins are secreted and translocated to host cells through this system. We recently demonstrated that secreted Hcp could bind to murine RAW 264.7 macrophages from outside and that it could also translocate into host cells, resulting in their apoptosis (Suarez et al., 2008). In this study, to examine the role of AHL-mediated QS in the regulation of the T6SS, we performed Western blot analysis to determine the produc- 
(a)

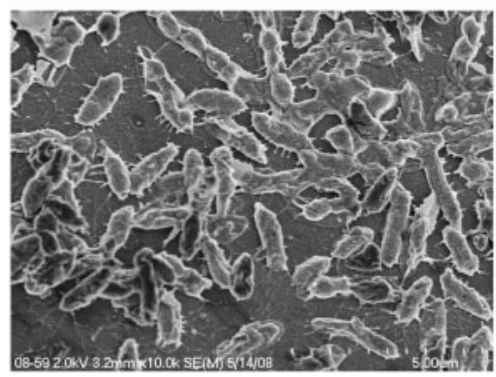

(c)

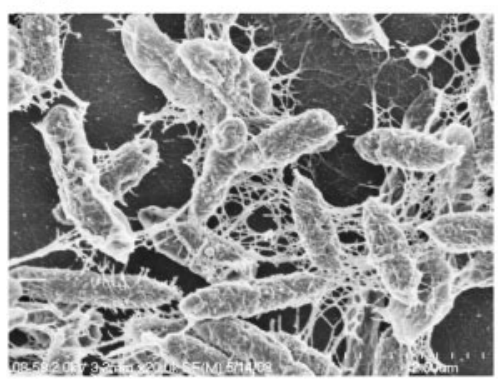

(e)

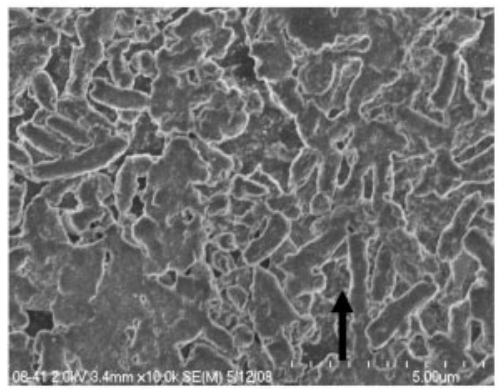

(b)

\section{$\triangle a h y R I$}

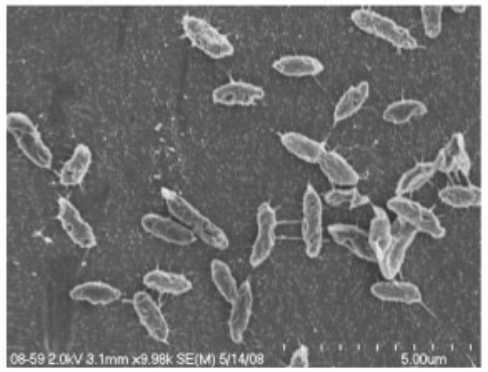

(d)

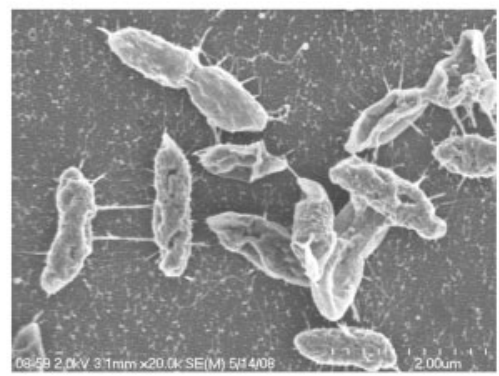

(f)

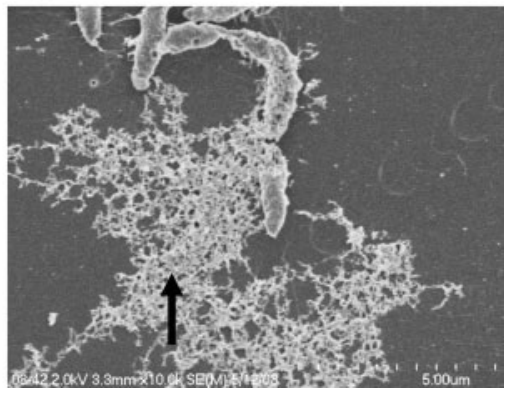

Fig. 2. SEM images of biofilm formation by WT A. hydrophila SSU and its $\Delta a h y R /$ mutant after $48 \mathrm{~h}$ cultivation at $37^{\circ} \mathrm{C}$ on Thermanox coverslips stained with ruthenium red. $(\mathrm{a}, \mathrm{c})$ Compact aggregation; cells were well connected with filaments in biofilm formed by the WT strain. (b, d) Less aggregated cells in the $\Delta a h y R /$ mutant biofilm, which were connected with fewer filaments compared with the biofilm formed by the WT bacteria. (e) A thick EPS was produced by the WT strain that was tightly bound to the surface of the cells (indicated by an arrow). (f) The $\Delta a h y R I$ mutant produced a distinct type of EPS compared with that of the WT strain, and the EPS was loosely bound to the surface of the cells (indicated by an arrow). tion and secretion of Hcp at different time points $(2 \mathrm{~h}$ and $4 \mathrm{~h})$ in WT, $\Delta a h y R I$ mutant and the $\Delta a h y R I / a h y R^{+} a h y I^{+}$ and $\Delta a h y R I / a h y R^{+}$(with C4-HSL) complemented strains of $A$. hydrophila SSU. We only show data on expression and secretion of Hcp in the WT, mutant and complemented strains at the $4 \mathrm{~h}$ time point, and the data at the $2 \mathrm{~h}$ time point are included in a supplementary figure.

We found that Hcp2 could be detected in bacterial cell pellets in both the WT and its $\triangle a h y R I$ mutant at $2 \mathrm{~h}$ (Supplementary Fig. S4, lanes 2 and 4 ) and $4 \mathrm{~h}$ (Fig. 3, lanes 2 and 4). However, in the WT bacteria, a significant amount of Hcp 2 was secreted into the medium at both $2 \mathrm{~h}$ (Supplementary Fig. S4, lane 1) and 4 h (Fig. 3, lane 1). In contrast, the $\triangle a h y R I$ mutant was unable to secrete Hcp2 at $2 \mathrm{~h}$ (Supplementary Fig. S4, lane 3) and 4 h (Fig. 3, lane 3). The $\Delta a h y R I / a h y R^{+} a h y I^{+}$complemented strain secreted Hcp2 to the WT level (Fig. 3, lane 5). Also, addition of C4HSL to the $\Delta a h y R I / a h y R^{+}$complemented stain restored Hcp2 secretion (Fig. 3, lane 7), which suggested to us that
AHL mediated the QS-regulated secretion of Hcp in $A$. hydrophila SSU.

\section{AHL-mediated QS also regulated secretion of another T6SS effector, VgrG}

As in V. cholerae (Pukatzki et al., 2006), there were three copies of the $v g r G$-encoded effector proteins, namely VgrG1, VgrG2 and VgrG3 in A. hydrophila SSU (Suarez et al., 2008). Furthermore, the role of VgrGs in cytotoxicity and virulence has recently been reported in $V$. cholerae (Pukatzki et al., 2006, 2009). However, the regulation of these VgrG effector molecules is currently unknown. In the present study, we examined whether AHL-mediated QS regulated the production and secretion of these VgrGs in $A$. hydrophila SSU.

In Western blot analysis, the production of VgrG2 effector was noted both in the WT and in the $\Delta a h y R I$ mutant of $A$. hydrophila SSU (Fig. 4, lanes 2 and 4, lower band). A 


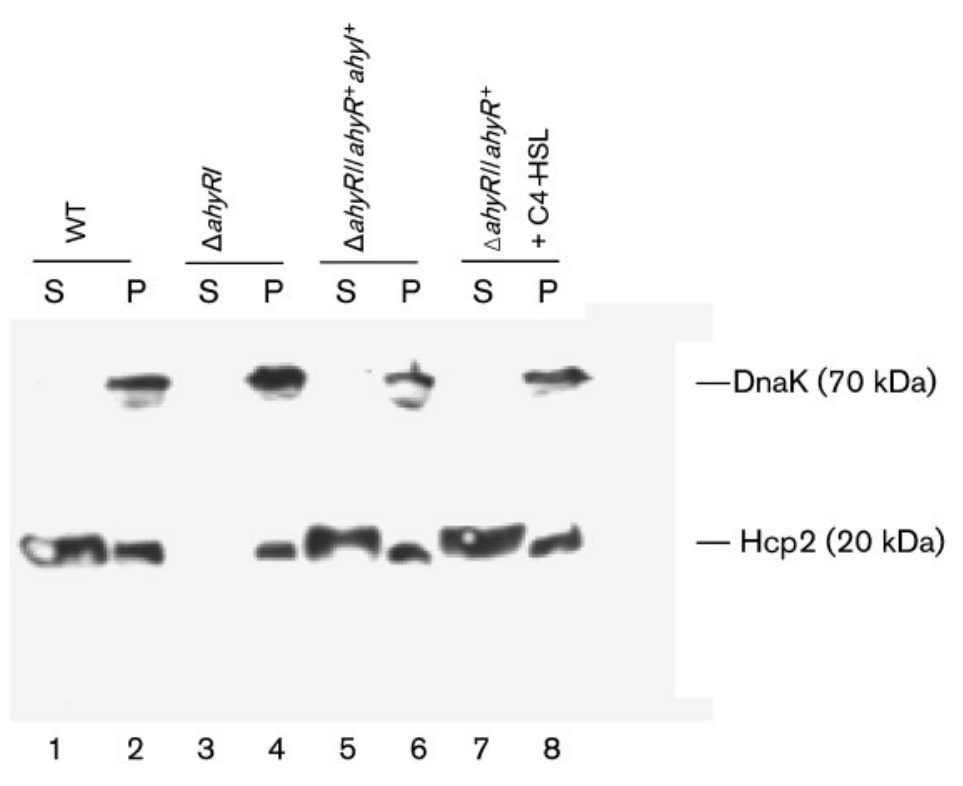

Fig. 3. Western blot analysis showing production of Hcp2 in the cell pellet $(P)$ and secretion of $\mathrm{Hcp} 2$ in the culture supernatants (S) of WT A. hydrophila SSU, the $\Delta a h y R I$ mutant and complemented strains. Lanes: 1, supernatant of WT strain; 2, cell pellet of WT strain; 3, supernatant of the $\Delta a h y R /$ mutant; 4, cell pellet of the $\Delta a h y R /$ mutant; 5 , supernatant of the $\Delta$ ahyRl/ahyR ${ }^{+}$ahyl ${ }^{+}$complemented strain; 6, cell pellet of the $\Delta$ ahyRII ahy $R^{+}$ahyl ${ }^{+}$complemented strain; 7, supernatant of the $\Delta$ ahyRl/ahy $R^{+}$complemented strain; 8, cell pellet of the $\Delta$ ahyRI/ahy $R^{+}$ complemented strain. The $\Delta a h y R / / a h y R^{+}$ complemented strain was grown in LB medium supplemented with $20 \mu \mathrm{M}$ C4-HSL. Polyclonal antibody against Hcp2 (at 1:1000 dilution) and secondary antibody (1:10000 dilution, goat anti-mouse $\operatorname{lgG}$ ) conjugated with horseradish peroxidase (HRP) were used. The blots were developed after reaction with SuperSignal West Pico chemiluminescence agent (Pierce) followed by X-ray film exposure. Anti-DnaK antibodies were used to measure the intactness of bacterial cells. Three independent experiments were performed. significant level of VgrG2 effector protein was secreted in the supernatant collected from the WT A. hydrophila SSU strain (Fig. 4, lane 1); however, the $\Delta a h y R I$ mutant was unable to secrete VgrG2 into the medium (Fig. 4, lane 3). Importantly, secretion of $\mathrm{VgrG} 2$ effector protein was restored in the $\Delta a h y R I$ complemented strain (Fig. 4, lane
5). Deletion of the $a s c V$ gene, which encodes an inner membrane component of the T3SS channel from $A$. hydrophila SSU, had no effect on the expression and secretion of these effector proteins (Fig. 4, lanes 7 and 8), which suggested that production and secretion of $\mathrm{VgrGs}$ were T3SS-independent. Overall, these results suggested to

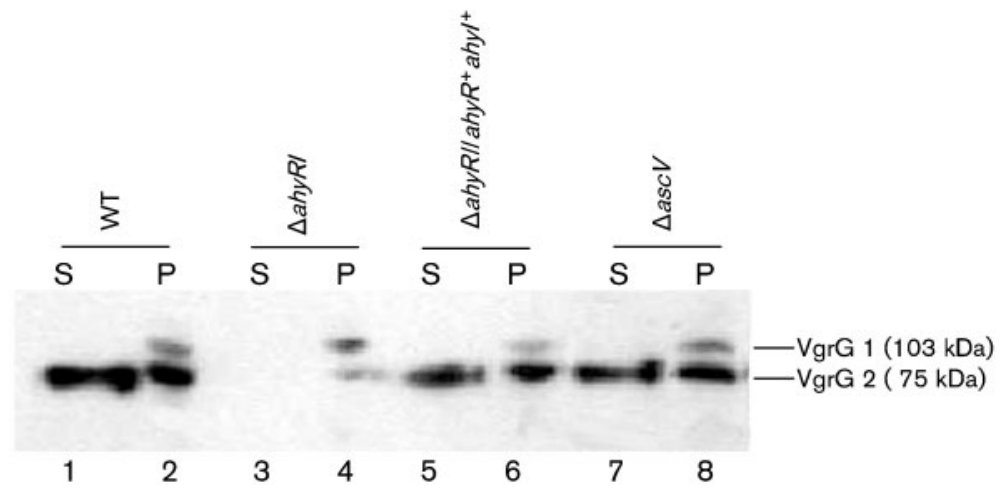

Fig. 4. Western blot analysis showing VgrG1 and $\mathrm{VgrG} 2$ production in the cell pellet $(P)$ and secretion of $\mathrm{VgrGs}$ in the culture supernatants (S) of WT $A$. hydrophila SSU, the $\Delta a h y R I$ mutant and complemented strains. Lanes: 1, supernatant of the WT strain; 2 , cell pellet of the WT strain; 3 , supernatant of the $\Delta$ ahyR/ mutant; 4 , cell pellet of the $\Delta a h y R /$ mutant; 5 , supernatant of the $\Delta$ ahy RI/ahy $R^{+}$ahyl ${ }^{+}$complemented strain; 6, cell pellet of the $\Delta a h y R I /$ ahy $R^{+}$ahyl ${ }^{+}$complemented strain; 7, supernatant of the $\Delta a s c V$ mutant; 8, cell pellet of the $\Delta$ ascV mutant. The ascV gene constitutes a component of the T3SS and was used as a control. Polyclonal antibody against VgrG2 (at $1: 1000$ dilution) and secondary antibody ( $1: 10000$ dilution, goat anti-mouse lgG) conjugated with HRP were used. The blots were developed after reaction with West Femto chemiluminescence substrate (Pierce) followed by X-ray film exposure. Results were reproduced through three independent experiments. 
us that AHL mediated the QS-controlled secretion of VgrG2 effector of T6SS in A. hydrophila SSU.

\section{Expression and translocation of AexU, a T3SS effector, was not affected in the $\Delta a h y R I$ mutant of A. hydrophila SSU}

To demonstrate regulation of the AHL-mediated QS on T3SS effector translocation, we examined expression of the aexU gene in bacterial cell pellets and translocation of AexU in human colonic epithelial (HT-29) cells in the WT and $\Delta a h y R I$ mutant grown in Dulbecco's Modified Eagle's Medium (DMEM). We found that the $\Delta a h y R I$ mutant had levels of production of AexU similar to those of WT bacteria (data not shown). Similarly, no difference in the translocation of AexU in HT-29 cells was noted after infection of the latter with the $\triangle a h y R I$ mutant and WT bacteria (data not shown). These data indicated that AHL-mediated QS had no effect on the expression and translocation of the T3SS effector AexU.

\section{The $\Delta a h y R I$ mutant showed decreased virulence in an animal model}

By using in vitro experiments, we demonstrated that deletion of the ahyRI genes from A. hydrophila SSU resulted in the decreased production of protease and prevented secretion of T6SS effectors, such as Hcp and VgrGs, and that the mutant was unable to produce mature biofilms. To examine whether these changes in virulence factors regulated by AHL-mediated QS had any influence on in vivo virulence of $A$. hydrophila SSU, we injected mice intraperitoneally with the $\Delta a h y R I$ mutant and the WT strain of A. hydrophila at a lethal dose of $3 \times 10^{7}$ c.f.u. (Fig. 5). We noted that $100 \%$ of the animals infected with the WT A. hydrophila died within 6 days. However, mice infected with the $\Delta a h y R I$ mutant strain exhibited significantly lower mortality (only $50 \%$ ) over a tested period of 16 days, which suggested to us that bacterial attenuation occurred when we deleted the ahyRI genes from $A$. hydrophila SSU.

\section{DISCUSSION}

In the present study, we examined the regulation of AHLmediated QS in modulating various virulence factors, including the T6SS and biofilm formation in a clinical isolate of A. hydrophila SSU. Interestingly, we showed that deletion of the luxS gene (AI-2-mediated QS) increased the overall virulence of $A$. hydrophila SSU (Kozlova et al., 2008). In contrast, deletion of the ahyRI genes decreased

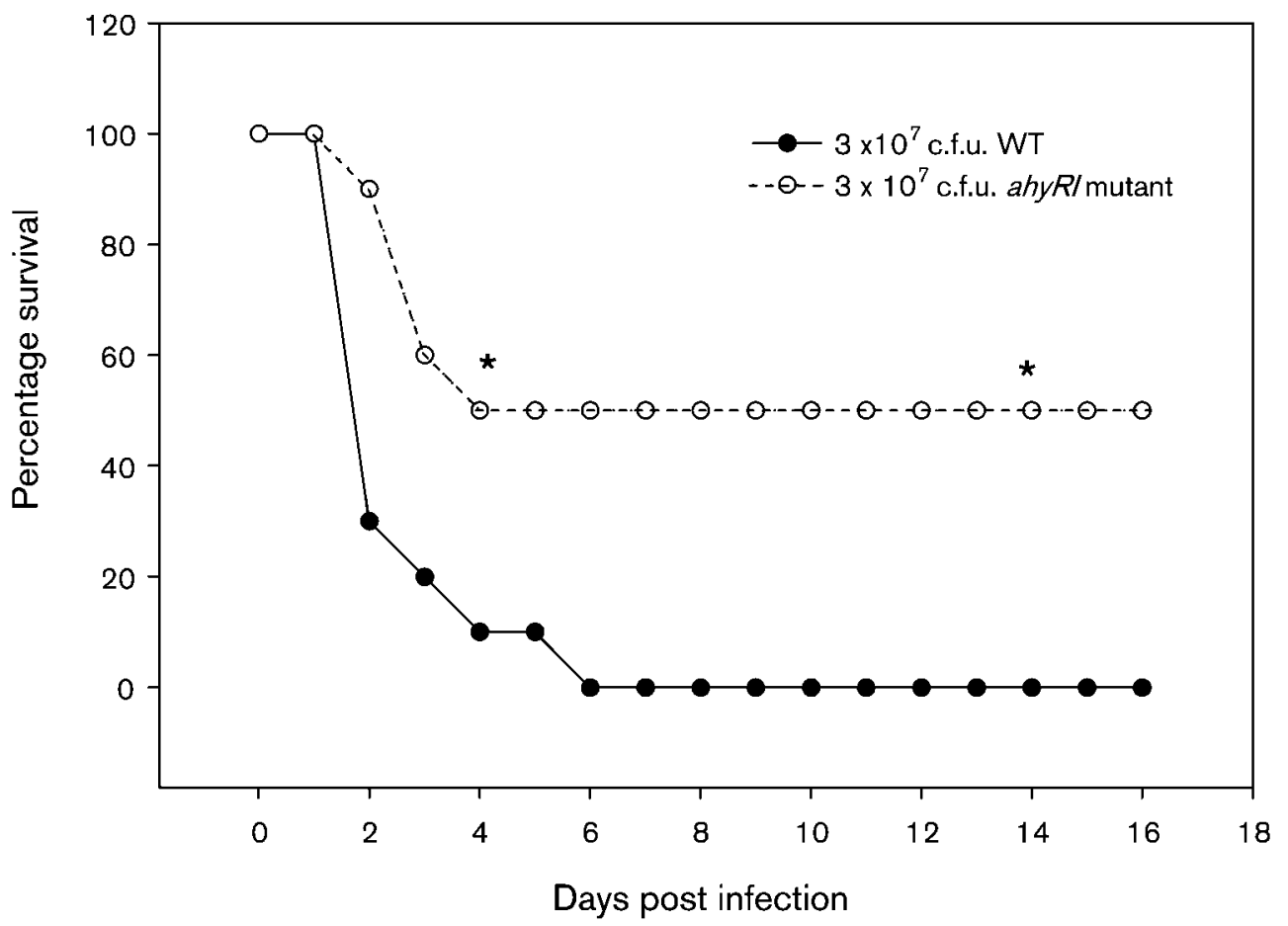

Fig. 5. The AhyRI QS regulon of $A$. hydrophila SSU contributes to the virulence of the bacterium. Swiss Webster mice ( $n=10$ per group) were injected intraperitoneally with two $50 \%$ lethal doses of WT A. hydrophila SSU. The same dose was used to infect mice with the $\Delta a h y R /$ mutant, and both groups were monitored for death over a 16 day period. The data were statistically analysed by using Fisher's exact test. Three independent experiments were performed, and data from a typical experiment are shown. The asterisks denote statistically significant differences between the ahyR/ mutant and WT bacteria $(P \leqslant 0.05)$. 
the virulence of this pathogen. Therefore, in A. hydrophila SSU, QS systems have both a positive and negative effect on regulation of virulence.

A role for protease in Aeromonas-associated tissue damage has been reported (Sakai, 1985), and in experimental animal models, the protease null mutants exhibit a decreased virulence both with A. hydrophila and Aeromonas salmonicida (Leung \& Stevenson, 1988; Sakai, 1985) compared with that of the WT bacteria. Moreover, the early expression of exoprotease may stimulate host defence (Swift et al., 1999), and therefore regulation of protease production by QS could be an important step in modulating host defence as well as in establishing an infection.

We observed, in agreement with earlier studies (Bi et al., 2007; Swift et al., 1999), that AHL mediated QS-regulated protease production in A. hydrophila SSU.

Based on casein zymogram analysis, three protein bands of sizes 61,52 and $19 \mathrm{kDa}$ were associated with protease activity of A. hydrophila SSU, and two of these higher molecular mass bands were missing from the $\Delta a h y R I$ mutant strain. We provided evidence that the $61 \mathrm{kDa}$ metalloprotease contributed to the majority of the protease activity $(81 \%)$ in $A$. hydrophila SSU. In contrast, a previous study showed that serine protease contributed approximately $60 \%$ and metalloprotease accounted for approximately $30 \%$ of the total protease activity in the A. hydrophila $\mathrm{AH}-1 \mathrm{~N}$ strain (Swift et al., 1999). By zymogram analysis, it was demonstrated that the $\Delta a h y I$ mutant did not produce the serine protease band (Swift et al., 1999). Interestingly, in our study, addition of serine protease inhibitor minimally affected the total protease activity of A. hydrophila SSU. The nature of the other two proteases needs to be further elucidated.

We provided evidence that deletion of the act gene, which is secreted through the T2SS in A. hydrophila SSU, decreased the production of AHL molecules (Sha et al., 2005). Consequently, we tested whether AHL-mediated QS regulated the function of Act. However, our study did not reveal any role of this AI-1 QS system in controlling the haemolytic and cytotoxic activities of this toxin in $A$. hydrophila SSU. We demonstrated that Act and T3SS- and T6SS-associated effectors contributed to cytotoxity in host cells in A. hydrophila SSU (Sha et al., 2005; Suarez et al., 2008). Although, AHL mediated the QS-regulated T6SS, we could not differentiate between the level of cytotoxicity in the $\triangle a h y R I$ mutant and that in the parental bacterium. These results indicated to us that cytotoxicity associated with Act and T3SS effectors could be masking T6SSassociated cytotoxic effects. In future studies, we will determine the cytotoxicity of the $\Delta a h y R I$ mutant in act and asc $V$ mutant strains of $A$. hydrophila SSU to discern the effect of T6SS on host cell toxicity. It will also be important to evaluate how Act might be modulating AHL levels in A. hydrophila SSU.

Motility is an important virulence factor of Gram-negative bacterial pathogens, as it helps them to reach the target host tissue to colonize and cause disease (Galindo et al., 2006). We noted a significantly decreased swimming motility in the $\Delta l u x S$ mutant of A. hydrophila SSU compared with that in the WT strain (Kozlova et al., 2008). However, deletion of the ahyRI QS regulon did not affect the swimming and swarming motility of $A$. hydrophila SSU, which was in accordance with an earlier study on Pseudomonas syringae in which the AHLmediated QS regulon did not affect motility in this plant pathogen (Kinscherf \& Willis, 1999). In contrast, in other pathogens (e.g. Erwinia chrysanthemi and Yersinia enterocolitica), deletion of the luxRI homologues produces either enhanced motility (Hussain et al., 2008) or decreased motility (Atkinson et al., 2006).

Biofilms are adherent aggregates of bacterial cells growing on biotic and abiotic surfaces. Biofilm-forming bacteria are less susceptible to host immune responses and various antimicrobial agents (Costerton et al., 1999). Importantly, biofilms are often associated with chronic infection, such as cystic fibrosis, caused by $P$. aeruginosa and catheterassociated biofilms of Staphylococcus epidermidis (Zhu \& Mekalanos, 2003). In biofilms, EPS is a key component that determines physicochemical and biological properties (Laue et al., 2006). Indeed, EPS is required for the initial attachment of $V$. cholerae (Watnick \& Kolter, 1999) and S. epidermidis to a solid surface (McKenney et al., 1998).

In the present study, a CV binding assay showed that the $\Delta a h y R I$ mutant of A. hydrophila SSU was defective in solid surface attachment, and SEM images further confirmed that the $\Delta a h y R I$ mutant strain produced a defective EPS on its surface which resulted in the formation of unstructured biofilms. Similar results have been reported in $P$. aeruginosa (Davies et al., 1998) and other pathogens, e.g. Serratia liquefaciens (Labbate et al., 2004), in which deletion of the homologous genes of the LuxRI QS system shows unstructured and frail biofilm formation.

More importantly, we noted that the $\Delta a h y R I$ mutant of $A$. hydrophila SSU was unable to secrete Hcp and that it was also defective in biofilm formation, suggesting that the secretion of this protein plays an important role in the development of biofilm. Indeed, a role for Hcp in biofilm development has been noted in $P$. aeruginosa (SoutheyPillig et al., 2005) and V. parahaemolyticus (Enos-Berlage et al., 2005). When these studies were performed, it was not known that Hcp is a T6SS effector. However, the underlying mechanism(s) that modulates biofilm formation through the T6SS effector Hcp is far from clear and needs further in-depth studies, not only in A. hydrophila SSU, but also in other pathogens.

Although the T6SS has recently been identified in several Gram-negative bacterial pathogens (Cascales, 2008; Mougous et al., 2006; Pukatzki et al., 2006, 2009), the identification of the mechanism(s) of secretion and translocation of its effectors is still in its infancy. Thus far, only the Hcp and VgrG family of proteins have been shown to be secreted and translocated into eukaryotic cells 
by this T6SS (Ma et al., 2009). Our recent study showed that A. hydrophila SSU possesses a functional T6SS, and that the effector protein Hcp is translocated into eukaryotic cells through this system and plays an important role in the virulence of this pathogen (Suarez et al., 2008).

VgrG proteins have different C-terminal extensions, which contain domains with different activities. For example, VgrG1 and VgrG3 from $V$. cholerae carry a repeat in structural toxin A (RtxA) and peptidoglycan-binding domains, respectively, while $\operatorname{VgrG}$ from $P$. aeruginosa carries a zinc metalloprotease domain (Pukatzki et al., 2007). Furthermore, it has been reported that VgrG1 of $V$. cholerae has actin cross-linking activities in eukaryotic cells which are associated with cell-rounding phenotypes (Ma et al., 2009; Pukatzki et al., 2006, 2007). Since T6SS has complex regulatory machinery, an optimal timing of gene expression of this cluster is necessary for its optimal function. We believe that AHL-mediated QS plays a crucial role in controlling this complex secretion machinery in $A$. hydrophila SSU.

We noted that the secretion of Hcp2 and VgrG2 in the supernatant was impaired when we deleted the AhyRI QS regulon from $A$. hydrophila SSU, which suggested to us that AHL mediated the QS-regulated secretion of these effector proteins. However, these effectors could still be detected in the cell pellet of the $\Delta a h y R I$ mutant strain at a similar level to that of the WT A. hydrophila SSU. We speculated that the absence of intercellular accumulation of T6SS effectors in the $\triangle a h y R I$ mutant strain could be due either to their rapid degradation and/or alternatively to the reduced expression of the corresponding genes, and this needs to be further investigated.

Furthermore, there are two copies of the $h c p$ gene ( $h c p 1$ and $h c p 2$ ) in the genome of $A$. hydrophila SSU, and because they are nearly identical ( $98 \%$ homology) and similar in size, it is possible that we could also be detecting Hcp1 on the Western blots when using polyclonal antibodies against Hcp2. Likewise, VgrG2 has high homology with VgrG3, and they are similar in size; consequently, we might be detecting VgrG3 along with VgrG2 on the Western blots by using VgrG2 antibodies. However, it is not known whether genes encoding $h c p 1$ and 2 are expressed and regulated similarly, as the $h c p 1$ gene is not located within the T6SS gene cluster (Suarez et al., 2008). However, both $\operatorname{vgrG2}$ and $v g r G 3$ are located within the T6SS gene cluster (Suarez et al., 2008). In A. hydrophila ATCC 7966 strain, the AHA gene designations are as follows: $h c p 1$ (AHA_1118); $h c p 2$ (AHA_1826); vgrG1 (AHA_1119); vgrG2 (AHA_1827); and vgrG3 (AHA_1848).

In a recent study on the plant pathogen Pectobacterium atrosepticum, it was shown for the first time that AHL mediates QS-regulated T6SS and its putative effectors Hcp and VgrGs (Liu et al., 2008). In addition, it was shown by microarray analysis that 11 of the 18 genes of the T6SS cluster are expressed at significantly lower levels in the expI mutant than in the WT Pectobacterium atrosepticum (Liu et al., 2008). This study is very provocative and provides the first clue that the AhyRI regulon might affect bacterial virulence by modulating the T6SS.

Since VgrGs have a high homology between them, we detected VgrG1 in the bacterial cell pellet by using antibodies against VgrG2 (Fig. 4, lanes 2 and 4, upper band). However, we could not detect VgrG1 in the culture supernatant of either the WT or its $\Delta a h y R I$ mutant strain (Fig. 4, lanes 1 and 3). Nonetheless, the production of VgrG1 was similar in the WT versus its $\Delta a h y R I$ mutant strain in bacterial pellets. It was recently shown that deletion of the $c l p V$ gene, an ATPase which provides energy for the secretion of T6SS effectors, inhibits their secretion, while the expression and production of these effector proteins are unaltered (Mougous et al., 2006). Likewise, we demonstrated in the vasK mutant that the secretion, but not the expression/production and translocation of Hcp, were affected, and that the vasK mutant was highly attenuated in a septicaemic mouse model of A. hydrophila infection.

In addition, we showed that mice infected with WT $A$. hydrophila SSU had circulating antibodies to Hcp, and animals immunized with recombinant Hcp were protected from subsequent challenge with WT bacterium (Suarez et al., 2008). These data clearly suggested to us that secreted Hcp played an important role in the virulence of this pathogen (Suarez et al., 2008). Therefore, we speculate that AHL-mediated QS regulates secretion of T6SS effectors by modulating other T6SS components, such as the vasK and $c l p V$ genes. However, further detailed studies are needed to delineate the mechanistic basis of how AHL-mediated QS regulates the T6SS in A. hydrophila SSU.

The T3SS has been identified in several Aeromonas species, and its role in the establishment of infection in the host determined (Burr et al., 2003; Sha et al., 2005, 2007; Vilches et al., 2004). Furthermore, studies have shown that QS modulates the T3SS either positively in enteropathogenic and enterohaemorrhagic E. coli (Sperandio et al., 1999) or negatively in $P$. aeruginosa, $Y$. pestis, Vibrio harveyi and Vibrio parahaemolyticus (Bleves et al., 2005; Gelhaus et al., 2009; Henke \& Bassler, 2004). However, in the present study, we noted that the AHL-mediated QS system had no role in the regulation of the T3SS effector AexU in $A$. hydrophila SSU. Similarly, we showed that deletion of the luxS gene from A. hydrophila SSU had no effect on the expression and translocation of AexU (Kozlova et al., 2008). In enterohaemorrhagic E. coli, the T3SS is regulated by the AI-3-mediated QS (Sperandio et al., 1999), and recently we identified the AI-3 QS in A. hydrophila SSU (unpublished data). In the future, we will examine the role of AI-3-mediated QS in regulating T3SS genes in A. hydrophila SSU.

There is limited information on the role of an AHLmediated QS in vivo model of infection. Our study on the septicaemic model of mouse infection indicated that the $\Delta a h y R I$ mutant of A. hydrophila SSU is significantly less 
virulent than the WT bacterium, which suggested to us that this AHL-mediated QS regulon contributes to the virulence of A. hydrophila SSU. The in vivo role of AHL-mediated QS has been well established in a report of an acute lung infection model of $P$. aeruginosa (Smith et al., 2002). Furthermore, AHLs have been detected in lung tissues of mice infected with P. aeruginosa (Wu et al., 2000), which is further evidence that these signalling molecules play a role in bacterial pathogenesis. In addition, deletion of LasRI and/or RhlRI QS systems from $P$. aeruginosa was found to result in significant attenuation in terms of its ability to colonize hosts, induce inflammation and cause mortality (Pearson et al., 2000; Rumbaugh et al., 1999; Smith et al., 2002; Tang et al., 1996; Wu et al., 2001). In a future study, we will delineate the direct role of AHL molecules in the pathogenesis of A. hydrophila SSU in a mouse model of infection.

In conclusion, we demonstrated that AHL-mediated QS plays a crucial role in modulating the virulence of $A$. hydrophila SSU, and these findings validated the notion that interference by AHL-mediated QS would be a promising target for the development of new-generation antimicrobial therapeutics.

\section{ACKNOWLEDGEMENTS}

This research was supported by grants from the National Institutes of Health/National Institute for Allergy and Infectious Disease (NIH/ NIAID) (AI041611), the American Water Works Association Research Foundation (AwwaRF) and the Environmental Protection Agency. The National Science Foundation (NSF) grant (EF-0334227) that was a conduit for getting the ATCC 7066 A. hydrophila genome sequenced is also acknowledged. B.K.K. is a recipient of the McLaughlin Predoctoral Fellowship, University of Texas Medical Branch (UTMB). We would like to thank Ms Wen Jule, Department of Experimental Pathology, UTMB, for electron microscopic studies. We thank Ms Mardelle Susman for her careful editing of the manuscript.

\section{REFERENCES}

Atkinson, S., Chang, C. Y., Sockett, R. E., Camara, M. \& Williams, P. (2006). Quorum sensing in Yersinia enterocolitica controls swimming and swarming motility. J Bacteriol 188, 1451-1461.

Bassler, B. L. \& Losick, R. (2006). Bacterially speaking. Cell 125, $237-$ 246.

Bi, Z. X., Liu, Y. J. \& Lu, C. P. (2007). Contribution of AhyR to virulence of Aeromonas hydrophila J-1. Res Vet Sci 83, 150-156.

Bleves, S., Soscia, C., Nogueira-Orlandi, P., Lazdunski, A. \& Filloux, A. (2005). Quorum sensing negatively controls type III secretion regulon expression in Pseudomonas aeruginosa PAO1. J Bacteriol 187, 3898-3902.

Burr, S. E., Stuber, K. \& Frey, J. (2003). The ADP-ribosylating toxin, AexT, from Aeromonas salmonicida subsp. salmonicida is translocated via a type III secretion pathway. J Bacteriol 185, 6583-6591.

Cascales, E. (2008). The type VI secretion toolkit. EMBO Rep 9, 735741.

Chopra, A. K. \& Houston, C. W. (1999). Enterotoxins in Aeromonasassociated gastroenteritis. Microbes Infect 1, 1129-1137.
Costerton, J. W., Stewart, P. S. \& Greenberg, E. P. (1999). Bacterial biofilms: a common cause of persistent infections. Science 284, 13181322.

Davies, D. G., Parsek, M. R., Pearson, J. P., Iglewski, B. H., Costerton, J. W. \& Greenberg, E. P. (1998). The involvement of cell-to-cell signals in the development of a bacterial biofilm. Science 280, 295298.

de Kievit, T. R. (2009). Quorum sensing in Pseudomonas aeruginosa biofilms. Environ Microbiol 11, 279-288.

de Kievit, T. R. \& Iglewski, B. H. (2000). Bacterial quorum sensing in pathogenic relationships. Infect Immun 68, 4839-4849.

Dudley, E. G., Thomson, N. R., Parkhill, J., Morin, N. P. \& Nataro, J. P. (2006). Proteomic and microarray characterization of the AggR regulon identifies a phe $U$ pathogenicity island in enteroaggregative Escherichia coli. Mol Microbiol 61, 1267-1282.

Edwards, R. A., Keller, L. H. \& Schifferli, D. M. (1998). Improved allelic exchange vectors and their use to analyze 987P fimbria gene expression. Gene 207, 149-157.

Enos-Berlage, J. L., Guvener, Z. T., Keenan, C. E. \& McCarter, L. L. (2005). Genetic determinants of biofilm development of opaque and translucent Vibrio parahaemolyticus. Mol Microbiol 55, 1160-1182.

Erova, T. E., Fadl, A. A., Sha, J., Khajanchi, B. K., Pillai, L. L., Kozlova, E. V. \& Chopra, A. K. (2006a). Mutations within the catalytic motif of DNA adenine methyltransferase (Dam) of Aeromonas hydrophila cause the virulence of the Dam-overproducing strain to revert to that of the wild-type phenotype. Infect Immun 74, 5763-5772.

Erova, T. E., Pillai, L., Fadl, A. A., Sha, J., Wang, S., Galindo, C. L. \& Chopra, A. K. (2006b). DNA adenine methyltransferase influences the virulence of Aeromonas hydrophila. Infect Immun 74, 410-424.

Erova, T. E., Sha, J., Horneman, A. J., Borchardt, M. A., Khajanchi, B. K., Fadl, A. A. \& Chopra, A. K. (2007). Identification of a new hemolysin from diarrheal isolate SSU of Aeromonas hydrophila. FEMS Microbiol Lett 275, 301-311.

Fassel, T. A. \& Edmiston, C. E., Jr (1999). Ruthenium red and the bacterial glycocalyx. Biotech Histochem 74, 194-212.

Ferguson, M. R., Xu, X. J., Houston, C. W., Peterson, J. W., Coppenhaver, D. H., Popov, V. L. \& Chopra, A. K. (1997). Hyperproduction, purification, and mechanism of action of the cytotoxic enterotoxin produced by Aeromonas hydrophila. Infect Immun 65, 4299-4308.

Galindo, C. L., Gutierrez, C., Jr \& Chopra, A. K. (2006). Potential involvement of galectin-3 and SNAP23 in Aeromonas hydrophila cytotoxic enterotoxin-induced host cell apoptosis. Microb Pathog 40, 56-68.

Gelhaus, H. C., Rozak, D. A., Nierman, W. C., Chen, D., Mojgan Zadeh, J. J., Ulrich, R. L. \& Adamovicz, J. J. (2009). Exogenous Yersinia pestis quorum sensing molecules $N$-octanoyl-homoserine lactone and $\mathrm{N}$-(3-oxooctanoyl)-homoserine lactone regulate the $\mathrm{LcrV}$ virulence factor. Microb Pathog 46, 283-287.

Greenberg, E. P. (1997). Quorum sensing in Gram-negative bacteria. ASM News 63, 371-377.

Henke, J. M. \& Bassler, B. L. (2004). Quorum sensing regulates type III secretion in Vibrio harveyi and Vibrio parahaemolyticus. J Bacteriol 186, 3794-3805.

Hussain, M. B., Zhang, H. B., Xu, J. L., Liu, O., Jiang, Z. \& Zhang, L. H. (2008). The acyl-homoserine lactone-type quorum-sensing system modulates cell motility and virulence of Erwinia chrysanthemi pv. zeae. J Bacteriol 190, 1045-1053.

Janda, J. M. \& Abbott, S. L. (1998). Evolving concepts regarding the genus Aeromonas: an expanding panorama of species, disease presentations, and unanswered questions. Clin Infect Dis 27, 332-344. 
Kinscherf, T. G. \& Willis, D. K. (1999). Swarming by Pseudomonas syringae B728a requires gacS (lemA) and gacA but not the acylhomoserine lactone biosynthetic gene ahlI. J Bacteriol 181, 4133-4136.

Kirke, D. F., Swift, S., Lynch, M. J. \& Williams, P. (2004). The Aeromonas hydrophila LuxR homologue AhyR regulates the $\mathrm{N}$-acyl homoserine lactone synthase, AhyI positively and negatively in a growth phase-dependent manner. FEMS Microbiol Lett 241, 109-117.

Kirov, S. M., Tassell, B. C., Semmler, A. B., O’Donovan, L. A., Rabaan, A. A. \& Shaw, J. G. (2002). Lateral flagella and swarming motility in Aeromonas species. J Bacteriol 184, 547-555.

Kirwan, J. P., Gould, T. A., Schweizer, H. P., Bearden, S. W., Murphy, R. C. \& Churchill, M. E. (2006). Quorum-sensing signal synthesis by the Yersinia pestis acyl-homoserine lactone synthase YspI. J Bacteriol 188, 784-788.

Kozlova, E. V., Popov, V. L., Sha, J., Foltz, S. M., Erova, T. E., Agar, S. L., Horneman, A. J. \& Chopra, A. K. (2008). Mutation in the $S$ ribosylhomocysteinase $(l u x S)$ gene involved in quorum sensing affects biofilm formation and virulence in a clinical isolate of Aeromonas hydrophila. Microb Pathog 45, 343-354.

Krovacek, K., Pasquale, V., Baloda, S. B., Soprano, V., Conte, M. \& Dumontet, S. (1994). Comparison of putative virulence factors in Aeromonas hydrophila strains isolated from the marine environment and human diarrheal cases in southern Italy. Appl Environ Microbiol 60, 1379-1382.

Kumari, A., Pasini, P. \& Daunert, S. (2008). Detection of bacterial quorum sensing $N$-acyl homoserine lactones in clinical samples. Anal Bioanal Chem 391, 1619-1627.

Labbate, M., Queck, S. Y., Koh, K. S., Rice, S. A., Givskov, M. \& Kjelleberg, S. (2004). Quorum sensing-controlled biofilm development in Serratia liquefaciens MG1. J Bacteriol 186, 692-698.

Laue, H., Schenk, A., Li, H., Lambertsen, L., Neu, T. R., Molin, S. \& Ullrich, M. S. (2006). Contribution of alginate and levan production to biofilm formation by Pseudomonas syringae. Microbiology 152, 2909-2918.

Leung, K. Y. \& Stevenson, R. M. (1988). Tn5-induced proteasedeficient strains of Aeromonas hydrophila with reduced virulence for fish. Infect Immun 56, 2639-2644.

Liu, H., Coulthurst, S. J., Pritchard, L., Hedley, P. E., Ravensdale, M., Humphris, S., Burr, T., Takle, G., Brurberg, M. B. \& other authors (2008). Quorum sensing coordinates brute force and stealth modes of infection in the plant pathogen Pectobacterium atrosepticum. PLoS Pathog 4, e1000093.

Lynch, M. J., Swift, S., Kirke, D. F., Keevil, C. W., Dodd, C. E. \& Williams, P. (2002). The regulation of biofilm development by quorum sensing in Aeromonas hydrophila. Environ Microbiol 4, 18-28.

Ma, A. T., McAuley, S., Pukatzki, S. \& Mekalanos, J. J. (2009). Translocation of a Vibrio cholerae type VI secretion effector requires bacterial endocytosis by host cells. Cell Host Microbe 5, 234-243.

McClean, K. H., Winson, M. K., Fish, L., Taylor, A., Chhabra, S. R., Camara, M., Daykin, M., Lamb, J. H., Swift, S. \& other authors (1997). Quorum sensing and Chromobacterium violaceum: exploitation of violacein production and inhibition for the detection of $\mathrm{N}$ acylhomoserine lactones. Microbiology 143, 3703-3711.

McKenney, D., Hubner, J., Muller, E., Wang, Y., Goldmann, D. A. \& Pier, G. B. (1998). The ica locus of Staphylococcus epidermidis encodes production of the capsular polysaccharide/adhesin. Infect Immun 66, 4711-4720.

Morohoshi, T., Nakamura, Y., Yamazaki, G., Ishida, A., Kato, N. \& Ikeda, T. (2007). The plant pathogen Pantoea ananatis produces $N$ acylhomoserine lactone and causes center rot disease of onion by quorum sensing. J Bacteriol 189, 8333-8338.
Mougous, J. D., Cuff, M. E., Raunser, S., Shen, A., Zhou, M., Gifford, C. A., Goodman, A. L., Joachimiak, G., Ordoñez, C. L. \& other authors (2006). A virulence locus of Pseudomonas aeruginosa encodes a protein secretion apparatus. Science 312, 1526-1530.

Nicodème, M., Grill, J. P., Humbert, G. \& Gaillard, J. L. (2005). Extracellular protease activity of different Pseudomonas strains: dependence of proteolytic activity on culture conditions. J Appl Microbiol 99, 641-648.

O'Toole, G. A. \& Kolter, R. (1998). Flagellar and twitching motility are necessary for Pseudomonas aeruginosa biofilm development. Mol Microbiol 30, 295-304.

Pearson, J. P., Feldman, M., Iglewski, B. H. \& Prince, A. (2000). Pseudomonas aeruginosa cell-to-cell signaling is required for virulence in a model of acute pulmonary infection. Infect Immun 68, 43314334.

Prentki, P. \& Krisch, H. M. (1984). In vitro insertional mutagenesis with a selectable DNA fragment. Gene 29, 303-313.

Pukatzki, S., Ma, A. T., Sturtevant, D., Krastins, B., Sarracino, D., Nelson, W. C., Heidelberg, J. F. \& Mekalanos, J. J. (2006). Identification of a conserved bacterial protein secretion system in Vibrio cholerae using the Dictyostelium host model system. Proc Natl Acad Sci U S A 103, 1528-1533.

Pukatzki, S., Ma, A. T., Revel, A. T., Sturtevant, D. \& Mekalanos, J. J. (2007). Type VI secretion system translocates a phage tail spike-like protein into target cells where it cross-links actin. Proc Natl Acad Sci U S A 104, 15508-15513.

Pukatzki, S., McAuley, S. B. \& Miyata, S. T. (2009). The type VI secretion system: translocation of effectors and effector-domains. Curr Opin Microbiol 12, 11-17.

Reading, N. C. \& Sperandio, V. (2006). Quorum sensing: the many languages of bacteria. FEMS Microbiol Lett 254, 1-11.

Rumbaugh, K. P., Griswold, J. A., Iglewski, B. H. \& Hamood, A. N. (1999). Contribution of quorum sensing to the virulence of Pseudomonas aeruginosa in burn wound infections. Infect Immun 67, 5854-5862.

Sakai, D. K. (1985). Loss of virulence in a protease-deficient mutant of Aeromonas salmonicida. Infect Immun 48, 146-152.

Schuster, M., Lostroh, C. P., Ogi, T. \& Greenberg, E. P. (2003). Identification, timing, and signal specificity of Pseudomonas aeruginosa quorum-controlled genes: a transcriptome analysis. J Bacteriol 185, 2066-2079.

Seshadri, R., Joseph, S. W., Chopra, A. K., Sha, J., Shaw, J., Graf, J., Haft, D., Wu, M., Ren, Q. \& other authors (2006). Genome sequence of Aeromonas hydrophila ATCC 7966T: jack of all trades. J Bacteriol 188, 8272-8282.

Sha, J., Kozlova, E. V. \& Chopra, A. K. (2002). Role of various enterotoxins in Aeromonas hydrophila-induced gastroenteritis: generation of enterotoxin gene-deficient mutants and evaluation of their enterotoxic activity. Infect Immun 70, 1924-1935.

Sha, J., Pillai, L., Fadl, A. A., Galindo, C. L., Erova, T. E. \& Chopra, A. K. (2005). The type III secretion system and cytotoxic enterotoxin alter the virulence of Aeromonas hydrophila. Infect Immun 73, 6446-6457.

Sha, J., Wang, S. F., Suarez, G., Sierra, J. C., Fadl, A. A., Erova, T. E., Foltz, S. M., Khajanchi, B. K., Silver, A. \& other authors (2007). Further characterization of a type III secretion system (T3SS) and of a new effector protein from a clinical isolate of Aeromonas hydrophila part I. Microb Pathog 43, 127-146.

Sierra, J. C., Suarez, G., Sha, J., Foltz, S. M., Popov, V. L., Galindo, C. L., Garner, H. R. \& Chopra, A. K. (2007). Biological characterization of a new type III secretion system effector from a clinical isolate of Aeromonas hydrophila - part II. Microb Pathog 43, 147-160. 
Smith, R. S., Harris, S. G., Phipps, R. \& Iglewski, B. (2002). The Pseudomonas aeruginosa quorum-sensing molecule $\mathrm{N}$-(3-oxododecanoyl)homoserine lactone contributes to virulence and induces inflammation in vivo. J Bacteriol 184, 1132-1139.

Southey-Pillig, C. J., Davies, D. G. \& Sauer, K. (2005). Characterization of temporal protein production in Pseudomonas aeruginosa biofilms. J Bacteriol 187, 8114-8126.

Sperandio, V., Mellies, J. L., Nguyen, W., Shin, S. \& Kaper, J. B. (1999). Quorum sensing controls expression of the type III secretion gene transcription and protein secretion in enterohemorrhagic and enteropathogenic Escherichia coli. Proc Natl Acad Sci U S A 96, 1519615201.

Suarez, G., Sierra, J. C., Sha, J., Wang, S., Erova, T. E., Fadl, A. A., Foltz, S. M., Horneman, A. J. \& Chopra, A. K. (2008). Molecular characterization of a functional type VI secretion system from a clinical isolate of Aeromonas hydrophila. Microb Pathog 44, 344-361.

Swift, S., Karlyshev, A. V., Fish, L., Durant, E. L., Winson, M. K., Chhabra, S. R., Williams, P., Macintyre, S. \& Stewart, G. S. (1997). Quorum sensing in Aeromonas hydrophila and Aeromonas salmonicida: identification of the LuxRI homologs AhyRI and AsaRI and their cognate $N$-acylhomoserine lactone signal molecules. J Bacteriol 179, 5271-5281.

Swift, S., Lynch, M. J., Fish, L., Kirke, D. F., Tomas, J. M., Stewart, G. S. \& Williams, P. (1999). Quorum sensing-dependent regulation and blockade of exoprotease production in Aeromonas hydrophila. Infect Immun 67, 5192-5199.

Tang, H. B., DiMango, E., Bryan, R., Gambello, M., Iglewski, B. H., Goldberg, J. B. \& Prince, A. (1996). Contribution of specific Pseudomonas aeruginosa virulence factors to pathogenesis of pneumonia in a neonatal mouse model of infection. Infect Immun 64, 37-43.
Vila, J., Ruiz, J., Gallardo, F., Vargas, M., Soler, L., Figueras, M. J. \& Gascon, J. (2003). Aeromonas spp. and traveler's diarrhea: clinical features and antimicrobial resistance. Emerg Infect Dis 9, 552-555.

Vilches, S., Urgell, C., Merino, S., Chacon, M. R., Soler, L., CastroEscarpulli, G., Figueras, M. J. \& Tomas, J. M. (2004). Complete type III secretion system of a mesophilic Aeromonas hydrophila strain. Appl Environ Microbiol 70, 6914-6919.

Waters, C. M. \& Bassler, B. L. (2006). The Vibrio harveyi quorumsensing system uses shared regulatory components to discriminate between multiple autoinducers. Genes Dev 20, 2754-2767.

Watnick, P. I. \& Kolter, R. (1999). Steps in the development of a Vibrio cholerae El Tor biofilm. Mol Microbiol 34, 586-595.

Wu, H., Song, Z., Hentzer, M., Andersen, J. B., Heydorn, A., Mathee, K., Moser, C., Eberl, L., Molin, S. \& other authors (2000). Detection of $N$ acylhomoserine lactones in lung tissues of mice infected with Pseudomonas aeruginosa. Microbiology 146, 2481-2493.

Wu, H., Song, Z., Givskov, M., Doring, G., Worlitzsch, D., Mathee, K., Rygaard, J. \& Høiby, N. (2001). Pseudomonas aeruginosa mutations in lasI and rhlI quorum sensing systems result in milder chronic lung infection. Microbiology 147, 1105-1113.

Xu, X. J., Ferguson, M. R., Popov, V. L., Houston, C. W., Peterson, J. W. \& Chopra, A. K. (1998). Role of a cytotoxic enterotoxin in Aeromonas-mediated infections: development of transposon and isogenic mutants. Infect Immun 66, 3501-3509.

Zheng, J. \& Leung, K. Y. (2007). Dissection of a type VI secretion system in Edwardsiella tarda. Mol Microbiol 66, 1192-1206.

Zhu, J. \& Mekalanos, J. J. (2003). Quorum sensing-dependent biofilms enhance colonization in Vibrio cholerae. Dev Cell 5, 647-656.

Edited by: J. G. Shaw 